\section{Quicker set times}

Kent Express supplies a range of impression materials, available from stock and from all leading dental companies including its own Kent Dental brand.

The Kent Press Plus range is an addition to Kent Dental's choice of impression materials. Kent Press Plus is a new, cured silicone range with hydrophilic properties which Kent Express claims offers better adhesion in the presence of saliva or water to deliver a sharper, more detailed impression.

Included in the Kent Press Plus product range is a wash range with new, rounded style cartridges which feature two separate nozzles to help eliminate cross contamination between base and catalyst. Setting times are regular set mixing time $30 \mathrm{sec}-$ onds, and fast set mixing time 30 seconds, with a maximum working time of 1 minute 15 seconds. For more information phone 01634878787.

Reader response number 54

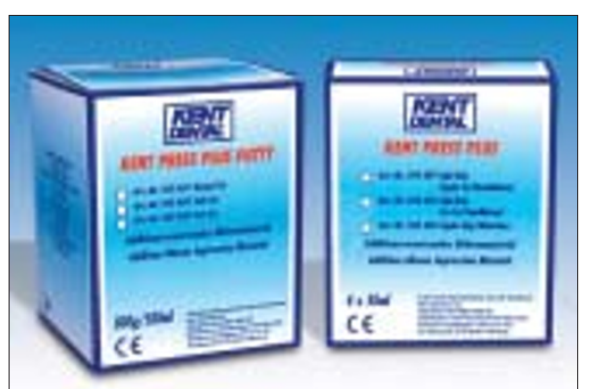

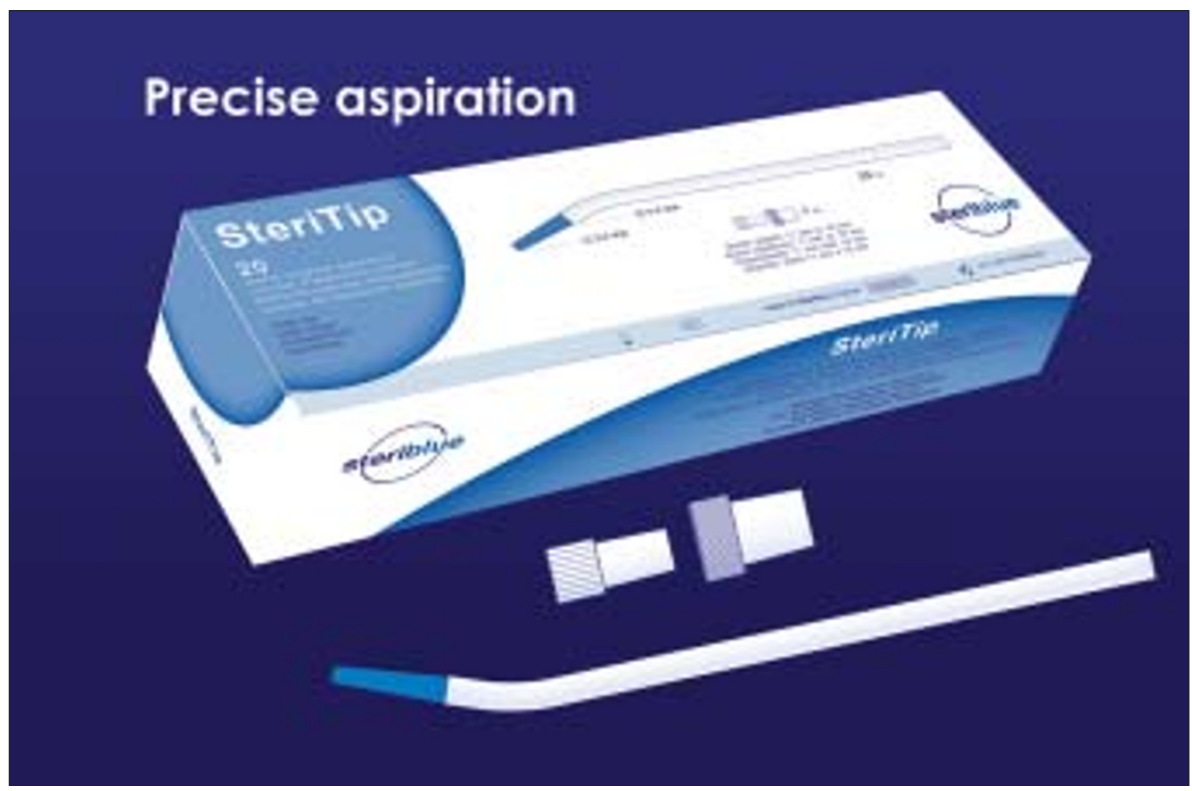

Bluejet aspirator tubes from Cardozo

Caradozo is pleased to announce the launch of the Bluejet aspirator tubes. Cardozo claims these are designed for excellent aspiration and incorporate a small rounded flange for both ease of use and patient comfort.

The tubes are autoclavable and available in five different colours for both 11 and $16 \mathrm{~mm}$ outlets. Babyjet tubes are produced to the same high specifications, but in a smaller size for both young and elderly patients.

Cardozo claims that for surgical procedures Steritip are the perfect tube with either $4.8 \mathrm{~mm}$ or $2.5 \mathrm{~mm}$ opening. Each Steritip is supplied in a sterile cell ready for use and each pack includes a double adaptor. Steritube $4.8 \mathrm{~mm}$ are supplied in bags of 100 and are the economical choice for accurate aspiration.

If you would like any further information or literature phone 01494773010.

Reader response number 55

\title{
A new brand of impression material from The Dental Directory
}

UnoDent Imprep is a new brand of impression material launched by the Dental Directory. The range offers dentists a variety of choices in terms of consistency and setting times. The Dental Directory claims the material has low shrinkage properties and high thixotrophy. It is available in both condensation cured (cc) and addition cured (ac) kits and cartridges.

The Dental Directory also claims that the Imprep is nontoxic and biocompatible in accordance with European regulations and that both putties and pastes are suitable for different applications; wash technique, double mixing etc and are available in a range of colours to enable the user to customise impressions.

For a demonstration in the surgery phone 0800585586 or fax 01376500581.

Reader response number 58

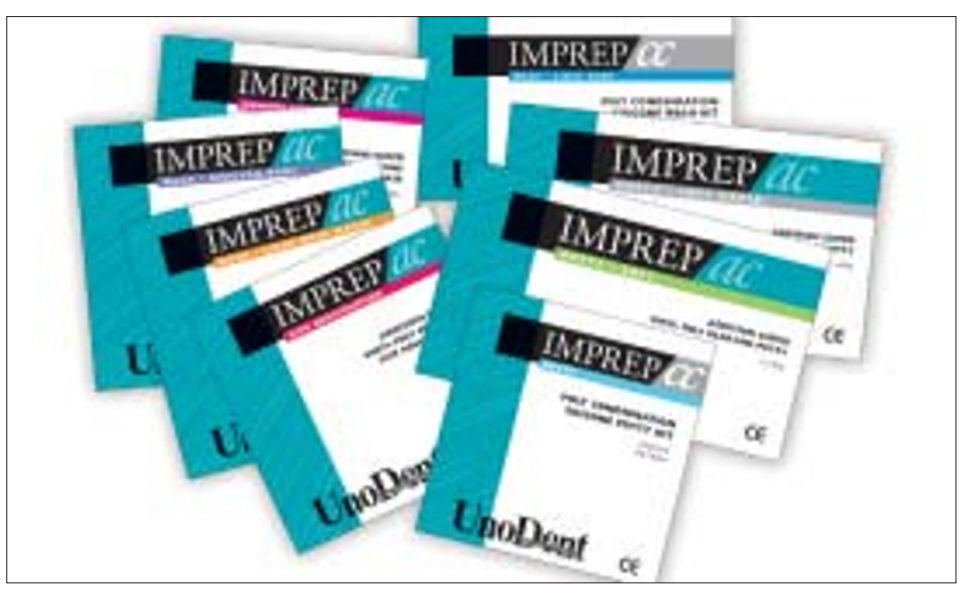




\section{Get better protection in the surgery}

Protection against infection concerns all members of the practice and extends to those who work in laboratories. Durr Dental offer a range of cleaning and disinfectants specifically for use on impressions and dentures. One of the product in the range is called the MD520.

Durr Dental claims MD520 has a wide range of applications; it can be used on alginates, silicones, polyether rubber, hydrocolloids and polysulphides. No reduction in the dimensional stability or plaster compatibility occurs and it is effective against a wide spectrum of bacteria, fungi and viruses.

MD520 is just one of a range of hygiene products made by Durr Dental. All are conveniently colour coded to identify each product. For more information phone Reader response number 59

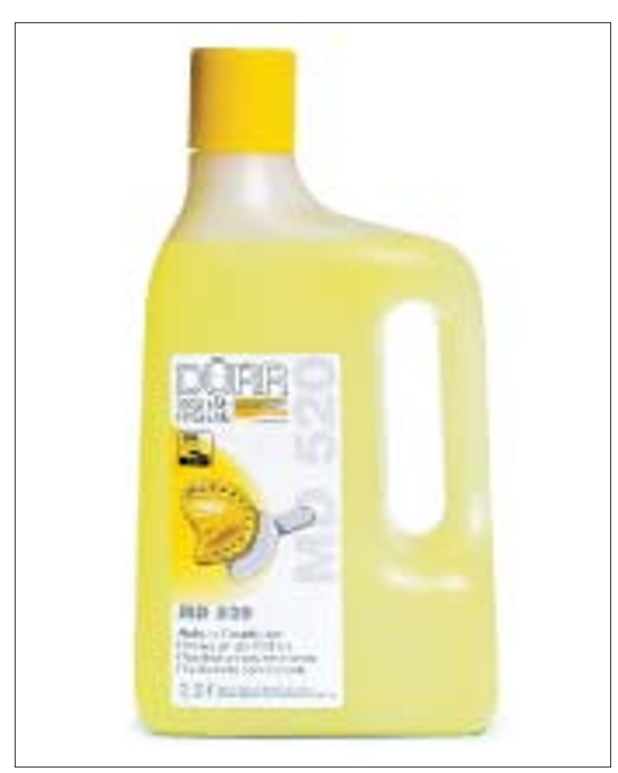

\section{A quick and simple solution for record taking}

The Centric Tray from Ivoclar Vivadent provides a quick and simple solution for taking a preliminary record of the patient's individual centric and vertical relationship.

Ivoclar Vivadent claims the Centric Tray is an ideal complement to the biofunctional

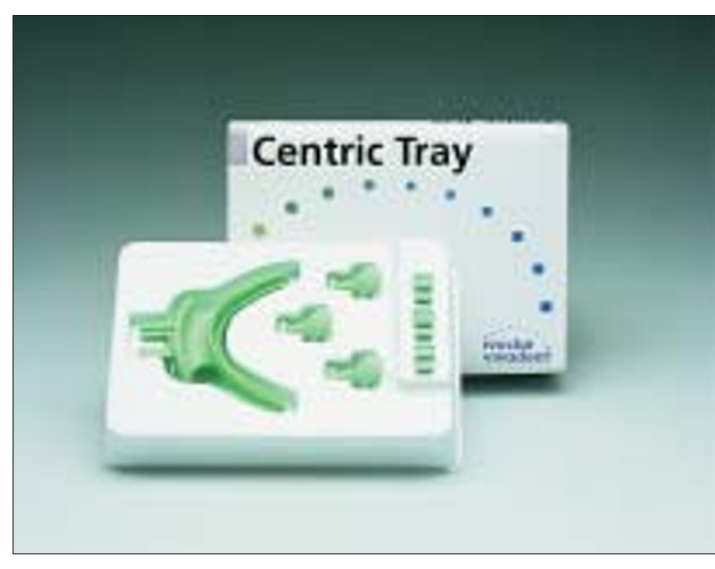
prosthetics system and that the resulting impression is used as a matrix to transfer information about the centric relation position to the dental laboratory.

Ivoclar Vivadent also claims existing models can then be accurately mounted in the articulator and subsequent steps to attaining an accurate centric relation record are made significantly easier.

For more information phone Ivoclar Vivadent on 0116265 4055.

Reader response number 60

\section{M ESPE launch the Express Penta $\mathrm{H}$}

3M ESPE is pleased to announce the launch of the new Express Penta $\mathrm{H}$ and Express Penta $\mathrm{H}$ Quick impression materials. These materials are vinyl polysiloxanes indicated for all crown and bridge impressions as well as inlay and onlays.

3M ESPE claims Express Penta products are formulated for automatic mixing and dispensing in 3M ESPE's pentamix 2 automatic mixing machine. They also claim that the automatic mixing guarantees effortlessly easy, repeatable results time after time. Express Penta $\mathrm{H}$ impression material offers a five minute setting time, Express Penta $\mathrm{H}$ Quick impression material sets after 3 and a half minutes.

For more information phone 01509613361.

Reader response number 61

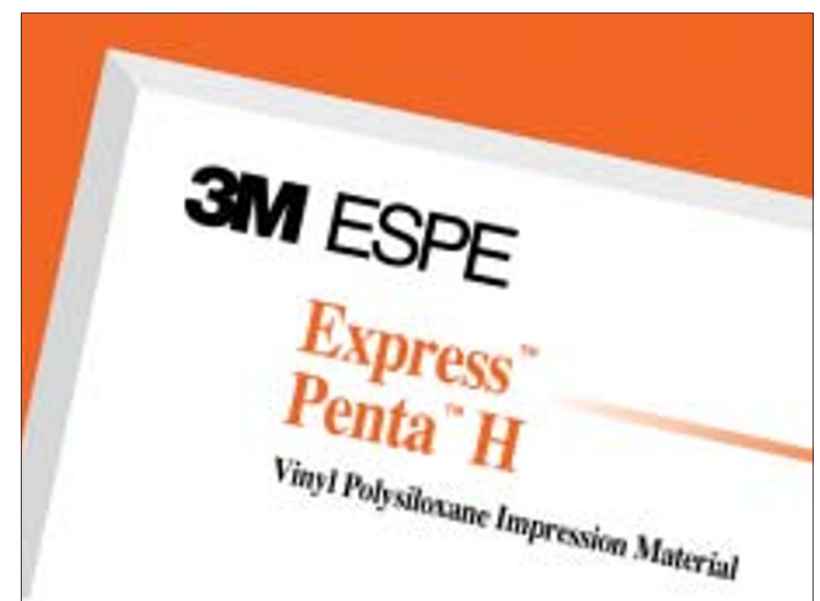

